\title{
PXR-mediated induction of P-glycoprotein by anticancer drugs in a human colon adenocarcinoma-derived cell line
}

\author{
Stefan Harmsen · I. Meijerman · C. L. Febus • \\ R. F. Maas-Bakker · J. H. Beijnen · J. H. M. Schellens
}

Received: 16 July 2009 / Accepted: 13 December 2009 / Published online: 30 December 2009

(C) The Author(s) 2009. This article is published with open access at Springerlink.com

\begin{abstract}
Purpose The development of multidrug resistance (MDR) is one of the major limitations in the treatment of cancer. Induction of P-glycoprotein (Pgp) has been regarded as one of the main mechanisms underlying anticancer drug-induced MDR. Since the induction of Pgp is (in part) regulated by the pregnane $\mathrm{X}$ receptor (PXR), the ability of several widely used anticancer drugs to activate PXR-mediated Pgp induction was investigated.

Methods A Pgp-reporter gene assay was employed to determine the ability of a panel of widely used anticancer drugs to induce Pgp. To further assess whether PXR could be involved in the induction of Pgp by anticancer drugs, Pgp protein expression after treatment with the anticancer drugs was determined in both wild-type and PXR-knocked down LS180 cells. Furthermore, the effect of the anticancer drugs on the intracellular accumulation of the Pgp-probes rhodamine 123 and doxorubicin was determined.
\end{abstract}

S. Harmsen $(\bowtie) \cdot$ I. Meijerman · C. L. Febus .

R. F. Maas-Bakker · J. H. Beijnen · J. H. M. Schellens

Division of Biomedical Analysis,

Department of Pharmaceutical Sciences, Faculty of Science,

Utrecht University, Sorbonnelaan 16, 3584 CA Utrecht,

The Netherlands

e-mail: s.harmsen@uu.nl

\section{J. H. Beijnen}

Department of Pharmacy and Pharmacology,

Slotervaart Hospital, Louwesweg 6,

1066 EC Amsterdam, The Netherlands

\section{J. H. M. Schellens}

Department of Medical Oncology,

The Netherlands Cancer Institute, Plesmanlaan 121,

1066 CX Amsterdam, The Netherlands
Results Our study showed that vincristine, tamoxifen, vinblastine, docetaxel, cyclophosphamide, flutamide, ifosfamide and paclitaxel activate PXR-mediated Pgp induction, and were additionally shown to affect the intracellular accumulation of the Pgp probe rhodamine 123. Moreover, PXR activation was also shown to reduce the cytotoxic activity of the Pgp substrate doxorubicin in colon cancer cells.

Conclusion Our results indicate that several anticancer drugs can activate PXR-mediated induction of Pgp and affect the accumulation of Pgp substrates.

Keywords PXR $\cdot$ Induction $\cdot$ P-glycoprotein $\cdot$ Multidrug resistance $\cdot$ Anticancer drugs

$\begin{array}{ll}\text { Abbreviations } \\ \text { ABC } & \text { ATP-binding cassette } \\ \text { ATP } & \text { Adenosine triphosphate } \\ \text { DMSO } & \text { Dimethylsulfoxide } \\ \text { HBSS } & \text { Hank's Balanced Salt Solution } \\ \text { HRP } & \text { Horse radish peroxidise } \\ \text { MDR } & \text { Multidrug resistance } \\ \text { NR } & \text { Nuclear receptor } \\ \text { PBS } & \text { phosphate buffer saline } \\ \text { Pgp } & \text { P-glycoprotein } \\ \text { PXR } & \text { Pregnane X receptor }\end{array}$

\section{Introduction}

A major drawback in the successful treatment of advanced malignancies is the development of multidrug resistance (MDR). One of the main causes by which cancer cells acquire the multidrug resistant phenotype in response to chemotherapy is the induction of ATP-binding cassette $(\mathrm{ABC})$ drug efflux transporter proteins. An important 
mediator of MDR that has been associated with poor treatment response in various malignancies is the $\mathrm{ABC}$-family member P-glycoprotein (Pgp; ABCB1; MDR1) [1-3]. Pgp is a transmembrane protein that protects the cell from xenobiotic stress by facilitating the extrusion of a broad spectrum of substrates, including anticancer drugs such as the anthracyclines, epipodophyllotoxins, Vinca alkaloids and taxanes. As a consequence, induction of Pgp affects the efficacy of these agents by decreasing their intracellular accumulation in cancer cells.

The pregnane X receptor (PXR; NR1I2) has been identified as a major regulator of Pgp induction [4], and, apart from expression in the liver and small intestines, has been shown to be expressed in several cancerous tissues such as breast, colon, bone, prostate and endometrial cancers [5-9]. PXR is a very promiscuous receptor that is activated by a wide variety of structurally unrelated ligands including rifampicin, hyperforin and the anticancer drug paclitaxel. Due to the promiscuity of PXR, possibly other widely used anticancer drugs could also activate PXRmediated Pgp induction, and as a consequence induce MDR in cancer cells.

In the current study, a panel of widely used anticancer drugs was evaluated for their ability to activate PXRmediated Pgp induction in the colon adenocarcinomaderived cell line LS180. In addition, the effect of PXR activation on the intracellular accumulation of Pgp substrates was determined. Our results demonstrate that several widely used anticancer drugs can activate PXR-mediated induction of Pgp and as a consequence decrease the intracellular accumulation of Pgp substrates. In addition, evidence is presented that the cytotoxic activity of doxorubicin is reduced when cells are pretreated with the PXR activator rifampicin.

\section{Materials and methods}

Materials

All cell culture media and supplements were purchased from Invitrogen (Breda, The Netherlands). Carboplatin, ifosfamide, tamoxifen citrate and etoposide were obtained from Axxora (San Diego, CA, USA). Zosuquidar (LY335979) was obtained through Kanisa Pharmaceuticals Inc. (Irvine, CA, USA). All other chemicals were purchased from Sigma-Aldrich (Zwijndrecht, The Netherlands).

\section{Plasmids}

The pGL3-MDR1 (p-10224) luciferase reporter construct was generously provided by Dr. Oliver Burk (Institute of Clinical Pharmacology, Eberhard-Karls University, Tübingen,
Germany). The pCDG-hPXR expression vector was generously provided by Dr. Ron Evans (Salk institute for biological studies, La Jolla, CA, USA). The pRL-TK control plasmid was obtained from Promega (Madison, WI, USA). Plasmids were checked by enzyme restriction and agarose gel electrophoresis and purified using Promega's Pureyield Midi-prep (Madison, WI, USA) according to the instructions of the manufacturer.

\section{Cell culture}

The human colon adenocarcinoma-derived cell line LS180 was purchased from the ATCC (Manassas, VA, USA). The cell-line was maintained in Roswell Park Memorial Institute (RPMI) 1640 medium (with $25 \mathrm{mM}$ HEPES and L-glutamine, supplemented with $10 \%(\mathrm{v} / \mathrm{v})$ heat-inactivated fetal bovine serum, $100 \mathrm{U} / \mathrm{ml}$ penicillin and $100 \mu \mathrm{g} / \mathrm{ml}$ streptomycin), at $37^{\circ} \mathrm{C}$ under a humidified atmosphere of $5 \% \mathrm{CO}_{2}$.

\section{Cell viability}

Cell viability was after $48 \mathrm{~h}$, and the anticancer drug treatment was assessed with a 3-(4,5-dimethylthiazol-2-yl)-2,5diphenyl tetrazolium bromide (MTT)-assay.

\section{Pgp reporter gene assay}

The Pgp reporter gene assay was performed in a similar manner as described previously [10]. In brief, LS180 cells were transfected with a pCDG-hPXR expression vector, a pGL3-MDR1 luciferase reporter construct, and a pRL-TK control plasmid for $24 \mathrm{~h}$. After transfection, the transiently transfected LS180 cells were treated with the highest non-toxic concentration of each anticancer drug. After $48 \mathrm{~h}$ incubation, the reporter activity was determined.

Cell treatment

LS180 cells were plated at a density of $5 \times 10^{4}$ cells/well in 96 well plates (Pgp protein level determination) or $1 \times 10^{5}$ cells/well in $1 \mathrm{ml}$ RMPI in 24 well plates (Pgp transport activity). After reaching 80-90\% confluency, medium was replaced with medium containing the different anticancer drugs: carboplatin $(10 \mu \mathrm{M})$, cyclophosphamide $(100 \mu \mathrm{M})$, ifosfamide $(100 \mu \mathrm{M})$, docetaxel $(10 \mu \mathrm{M})$, paclitaxel $(10 \mu \mathrm{M})$, flutamide $(10 \mu \mathrm{M})$ and tamoxifen $(10 \mu \mathrm{M})$. Rifampicin $(10 \mu \mathrm{M})$ was used as a positive control and DMSO $(0.1 \%)$ as a negative control. The cells were treated for $48 \mathrm{~h}$ with the drugs and the controls. At the end of each treatment, the cells were processed for immunoblotting or rhodamine 123-based Pgp activity assays. 


\section{RNA interference of PXR}

The siRNA sequence targeting human PXR (sense: cguuuguucgcuuccugagtt; antisense: cucaggaagcgaacaaacgtg) and the negative control, which consisted of a non-complementary sequence, were purchased from Ambion (Austin, TX, USA). LS180 cells were reversely transfected $48 \mathrm{~h}$ prior to the Pgp induction experiment with $50 \mathrm{nM}$ siRNA PXR or $50 \mathrm{nM}$ negative control siRNA using Lipofectamine RNAi Max (Invitrogen, Breda, The Netherlands). Subsequently, PXR knockdown and control LS180 cells were treated with different anticancer drugs for $48 \mathrm{~h}$.

\section{Immunoblot analysis}

After $48 \mathrm{~h}$ of culture, cells were washed with phosphatebuffered saline (PBS), and lysed in $1 \mathrm{ml} /$ well MilliQ water that contained protease inhibitors (Roche, Basal, Switzerland). The lysate was centrifuged $\left(5,000 \mathrm{rpm}, 5 \mathrm{~min}, 4^{\circ} \mathrm{C}\right)$, and the remaining pellet was resuspended in $100 \mu \mathrm{L}$ RIPA buffer. The lysate was centrifuged $\left(10,000 \mathrm{rpm}, 5 \mathrm{~min}, 4^{\circ} \mathrm{C}\right)$ and the supernatant was transferred to a new collection tube. Protein concentrations were determined by a Pierce BCA protein assay (Pierce, Rockford, IL, USA). Ten micrograms of total protein was separated by SDSpolyacrylamide gel electrophoresis using NuPage novex 4-12\% bis-tris gradient gels (Invitrogen, Breda, The Netherlands). Proteins were electroblotted onto Immobilon P membranes (Millipore, Bedford, MA, USA). After blocking ( $1 \mathrm{~h}$ at RT) in 3\% BSA in tris-buffered saline containing $0.1 \%$ Tween-20, the membranes were incubated overnight at $4^{\circ} \mathrm{C}$ with a murine monoclonal anti-Pgp primary antibody (C219, 1:500; Abcam, Cambridge, UK) followed by incubation with a goat anti-mouse $\operatorname{IgG}$ coupled to horse radish peroxidase (HRP) secondary antibody (1:1,000; ImmunoPure Peroxidase Conjugated Goat anti-Mouse IgG $(\mathrm{H}+\mathrm{L})$; Pierce, Rockford, IL, USA). $\beta$-actin $(1: 10,000$; AC-15; Abcam, Cambridge, UK) was used as a loading control. The proteins were visualized by a chemiluminescence-based detection reagent (SuperSignal West Femto; Pierce, Rockford, IL, USA), and the intensities of the Pgp bands were determined on a Gel Doc XRS Imaging system with Quantity One analysis software (Bio-Rad, Hercules, CA, USA). The ratio of the Pgp signal and the $\beta$-actin signal were indicative for Pgp protein expression.

\section{Rhodamine 123 accumulation assay}

The efflux activity of Pgp was determined by measuring the accumulation of the fluorescent Pgp probe rhodamine 123 as described by Collett et al. [11]. In brief, LS180 cells were pretreated with the anticancer drugs as described earlier. After $48 \mathrm{~h}$, the cells were washed with Hank's
Balanced Salt Solution (HBSS) and incubated at $37^{\circ} \mathrm{C}$ for $1 \mathrm{~h}$ with rhodamine $123(10 \mu \mathrm{M})$ in the presence or absence of the Pgp-specific inhibitor zosuquidar (LY335979; $5 \mu \mathrm{M}$; [12]) in phenol red-free RPMI medium. After washing thrice with ice-cold HBSS, the cells were lysed with Triton X-100 (0.1\%) in MilliQ water (Millipore, Bedford, MA, USA). The ratio of intracellular rhodamine 123 concentrations in the absence and presence of $5 \mu \mathrm{M}$ zosuquidar is indicative for the efflux activity of Pgp.

\section{Doxorubicin accumulation}

LS180 cells $\left(0.5 \times 10^{6} \mathrm{c} /\right.$ well $)$ were plated in a 24 -well plate. After a $48 \mathrm{~h}$ incubation with $0.1 \%$ DMSO or $10 \mu \mathrm{M}$ rifampicin, cells were treated with $5 \mu \mathrm{M}$ doxorubicin for $90 \mathrm{~min}$. Cells were washed thrice with ice-cold PBS, lysed in $250 \mu \mathrm{l}$ MilliQ water, and homogenized by ultrasonification Labsonic P (Braun; cycle 0.2 min en Amplitude 60\%). Hundred microliters of the homogenate was processed for HPLC analysis. Daunorubicin was used as an internal standard. The samples and standard solutions were prepared as described by van Asperen et al. [13].

\section{Doxorubicin HPLC analysis}

Doxorubicin was quantified using a method as previously described by DeGregorio et al. [14]. In brief, samples were eluted isocratically with a mobile phase that consisted of $28 \%$ acetonitrile in $60 \mathrm{mM}$ phosphoric acid. A Waters Symmetry C18 $3.5 \mu \mathrm{M}, 4.6 \mathrm{~mm} \times 100 \mathrm{~mm}$ reverse-phase column was used. Fluorescence was detected using a JASCO FP-920 fluorometer (excitation: $455 \mathrm{~nm}$; emission: $550 \mathrm{~nm}$ ), Shimadzu LC10AT-VP pumps and a Shimadzu SCL10A-VP controller. The flow rate was set at $1.0 \mathrm{ml} /$ min. Doxorubicin and daunorubicin retention times were 2.38 and $5.01 \mathrm{~min}$, respectively. A standard curve of doxorubicin $(0.08,0.4,2,10$ and $50 \mu \mathrm{M})$ was prepared in milliQ water.

\section{Doxorubicin cytotoxicity assay}

LS180 cells were plated $\left(2 \times 10^{4}\right.$ cells/well; 96 well plates $)$ and treated with $10 \mu \mathrm{M}$ rifampicin or $0.1 \%$ DMSO. Following $72 \mathrm{~h}$ incubation, cells were exposed to doxorubicin (serially diluted $0-20 \mu \mathrm{M}$; dilution factor 2). Cell viability after $48 \mathrm{~h}$ doxorubicin exposure was assessed using a neutral red assay [15].

\section{Statistical analysis}

One-way ANOVA with Bonferroni post hoc testing was performed for statistical comparison of the obtained Pgp reporter gene and activity results and considered statistically 


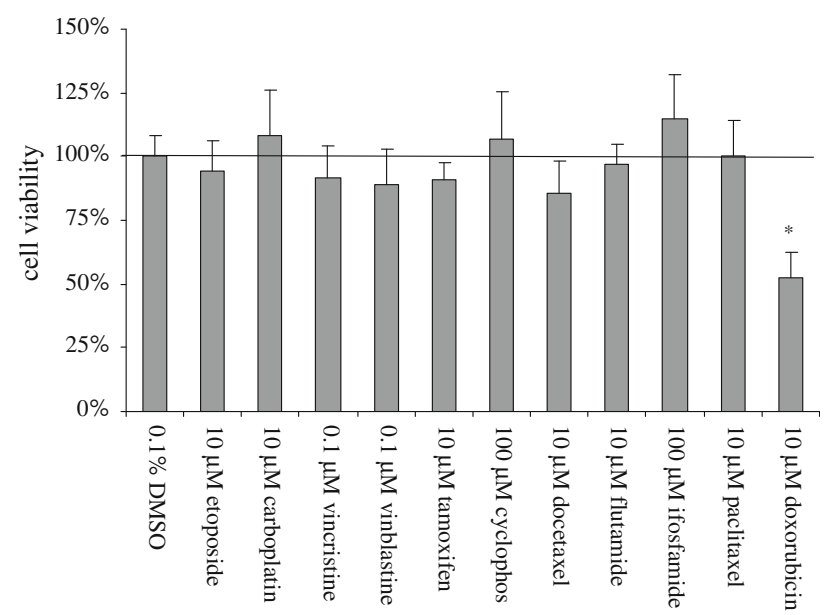

Fig. 1 Cell viability after treatment with different anticancer drugs. LS180 cells were treated for $48 \mathrm{~h}$ with different anticancer drugs. Cell viability was assessed with a MTT-assay

significant when $P<0.05$. All statistical calculations were done in SPSS (v14, SPSS Inc. Chicago, IL, USA).

\section{Results}

\section{Cell viability}

Cell viability was assessed after $48 \mathrm{~h}$ treatment with different concentrations of the anticancer drugs. As shown in Fig. 1, the anticancer drugs did not significantly affect the
LS180 cell viability at the concentrations used, while the doxorubicin $(10 \mu \mathrm{M})$ did affect cell viability.

PXR-mediated Pgp reporter activation by anticancer drugs

The ability of widely used anticancer drugs to induce the expression of Pgp via activation of PXR was determined. LS180 cells were transfected with a Pgp reporter construct as well as a PXR expression plasmid. Treatment of the transiently transfected LS180 cells with cyclophosphamide, ifosfamide, docetaxel, paclitaxel, flutamide, and tamoxifen resulted in dose-dependent increases in Pgp reporter activity, while exposure to different concentrations of carboplatin and etoposide did not increase PXR-mediated Pgp reporter activity (Fig. 2). As a control, the same compounds were tested in LS180 cells that were only transfected with the Pgp reporter gene construct without co-transfection of a PXR expression plasmid. In these cells, none of the compounds was able to activate Pgp reporter activity (results not shown).

\section{Induction of Pgp protein expression}

To evaluate whether Pgp reporter activation is predictive for Pgp protein induction, the effect of the anticancer drugs on the protein expression levels of Pgp after $48 \mathrm{~h}$ treatment in LS180 cells was determined. As shown in Fig. 3, all compounds that were shown to activate PXR-mediated Pgp reporter activity (vincristine, tamoxifen, vinblastine, doce-

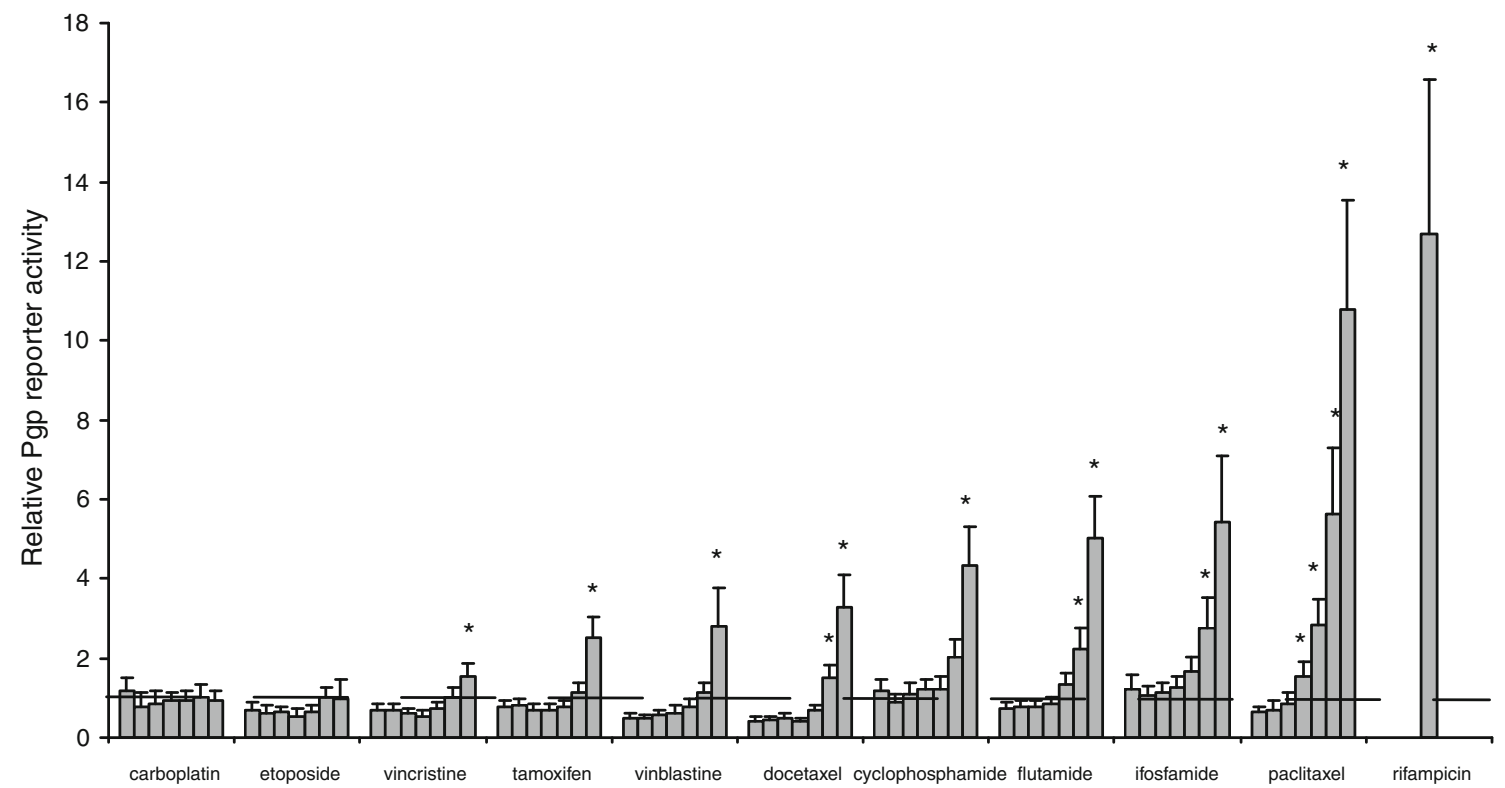

Fig. 2 PXR-mediated Pgp reporter gene activity following exposure to anticancer drugs. LS180 cells were transfected with the pGL3MDR1 reporter construct, the nuclear receptor expression vectors pCDG-hPXR, and the pRL-TK control vector. Cells were exposed to anticancer drugs (range: $0.1-10 \mu \mathrm{M}$; dilution factor 3 ) with the exception ifosfamide and cyclophosphamide $(0.3-100 \mu \mathrm{M}$; dilution factor 3). Rifampicin $(10 \mu \mathrm{M})$ was used as positive control. These results are the means $( \pm \mathrm{SD})$ of three separate determinations and are expressed as relative fold inductions compared to $0.1 \%$ DMSO $(* P<0.05)$ 


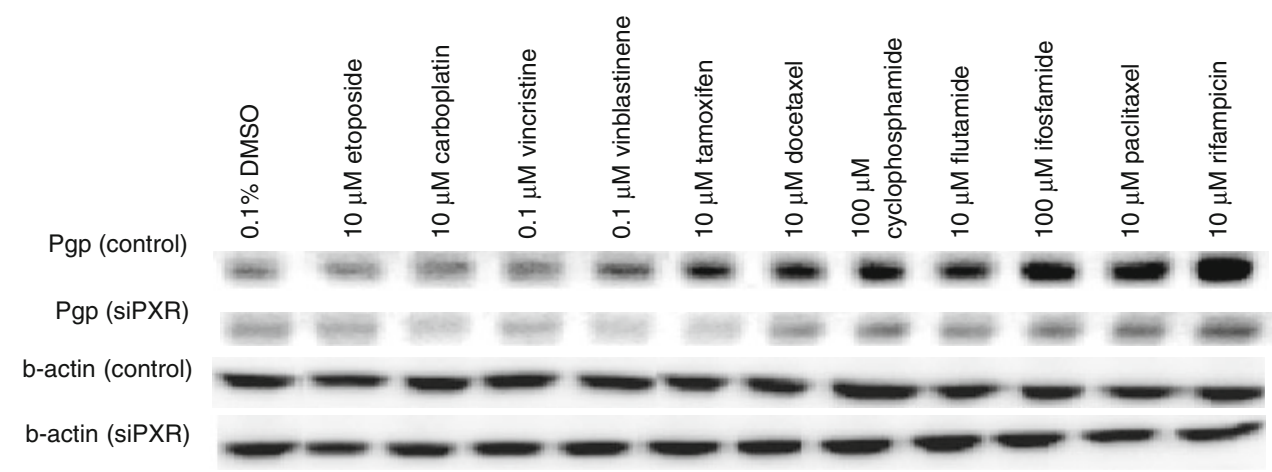

Fig. 3 Anticancer drugs affect Pgp protein expression. Pgp protein expression after exposure of the LS180 to the anticancer drugs as was determined with immunoblotting using Pgp- and $\beta$-actin-specific anti- bodies. The figure shows a representative immunoblot of Pgp protein expression in LS180 cells (both in control and PXR knock down cells) following $48 \mathrm{~h}$ treatment with the indicated anticancer drugs taxel, cyclophosphamide, flutamide, ifosfamide and paclitaxel) also induced Pgp protein levels in LS180 cells. In accordance with the Pgp-reporter gene assay, both etoposide and carboplatin did not induce Pgp protein expression. To further demonstrate that PXR plays an important role in the upregulation of Pgp, PXR was knocked down in the LS180 cells (knock down efficiency was $51 \%$ as was determined $48 \mathrm{~h}$ after siRNA transfection by Western blot (results not shown)). The cells were subsequently treated with the anticancer drugs. As shown in Fig. 3, Pgp protein induction was significantly lower in the PXR knockdown LS180 cells after treatment with the anticancer drugs compared to the control cells (LS180 cells transfected with non-targeting siRNA). However, Pgp induction was not completely abolished, most likely as a result of the knockdown efficiency of $51 \%$.
Rhodamine 123 accumulation assay

To assess whether PXR-mediated Pgp induction affects the accumulation of Pgp substrates, the transport activity of Pgp was analyzed using a rhodamine 123 accumulation assay. Following $48 \mathrm{~h}$ pretreatment with the anticancer drugs, cells were exposed to rhodamine 123 in the absence or presence of the Pgp-specific inhibitor zosuquidar (LY335979; IC50 $=4 \mathrm{nM}$ ) [16]. The ratio between the intracellular fluorescence of rhodamine 123 in the presence and absence of zosuquidar is indicative for the Pgp transport activity in the treated LS180 cells [11]. As shown in Fig. 4, rhodamine 123 accumulation corresponds with Pgp protein expression data; low cellular rhodamine 123 accumulation was observed for paclitaxel, docetaxel and flutamide, which were shown to induce Pgp protein expression,

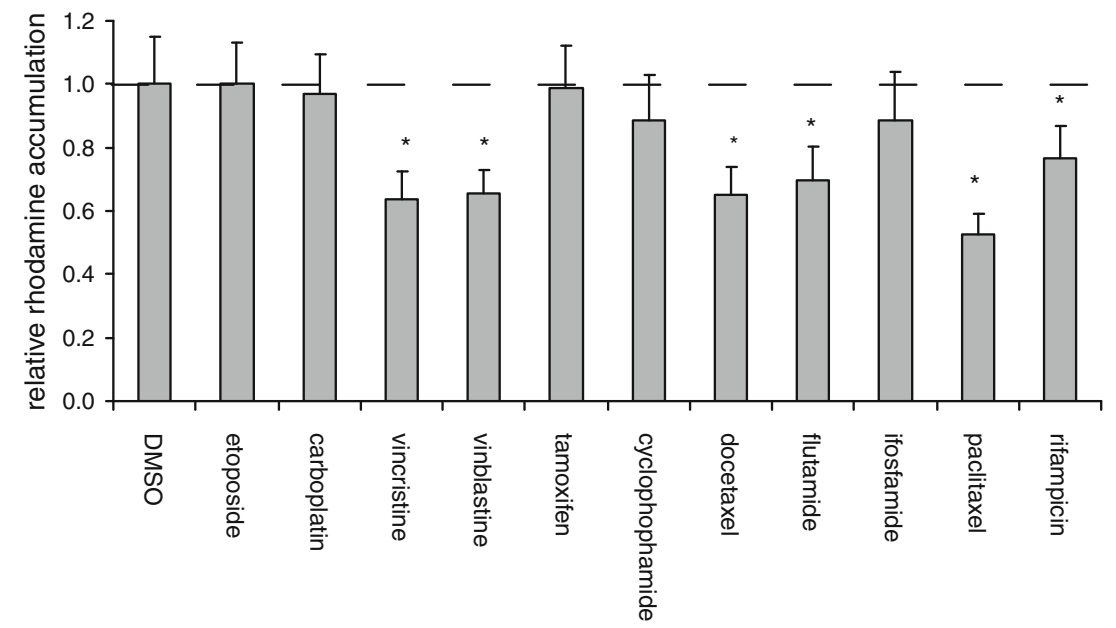

Fig. 4 Anticancer drug pretreatment affects Pgp substrate accumulation. LS180 cells were exposed to the indicated anticancer drugs for $48 \mathrm{~h}$, after which rhodamine 123 accumulation was determined in the absence or presence of the Pgp-specific inhibitor zosuquidar. The ratio of intracellular rhodamine 123 fluorescence in the absence or presence of zosuquidar is indicative for the functionality of Pgp. The data are normalized to the DMSO controls and are presented as mean data $( \pm \mathrm{SD})$ of three different experiments $(* P<0.05)$ 
while etoposide and carboplatin did not affect rhodamine 123 accumulation. In contrast, the accumulation of rhodamine 123 in the cells that were treated with the Vinca alkaloids, cyclophosphamide, ifosfamide and tamoxifen did not correspond with Pgp protein expression.

\section{Effect of PXR activation on doxorubicin cytotoxicity}

To study whether activation of PXR affects the efficacy of a cytotoxic Pgp substrate, the effect of PXR activation on the cytotoxicity of doxorubicin in LS180 was assessed. Therefore, prior to doxorubicin exposure, LS180 cells were pretreated with the prototypical PXR agonist $10 \mu \mathrm{M}$ rifampicin or $0.1 \%$ DMSO (solvent) for 48 h. As shown in Fig. 5a, rifampicin pretreatment affects the intracellular accumulation of doxorubicin. To determine whether reduced accumulation of doxorubicin also affects the efficacy of this agent, rifampicin- or solvent- pretreated cells were exposed to different doxorubicin concentrations (ranging from 0.3 to $20 \mu \mathrm{M}$; dilution factor 2). As shown in Fig. 5b, following doxorubicin exposure cell viability was significantly $(P<0.05)$ higher in the rifampicin- pretreated cells $\left(\mathrm{IC}_{50}=2.5 \mu \mathrm{M}\right)$ compared to the solvent (0.1\% DMSO) pretreated cells $\left(\mathrm{IC}_{50}=1.5 \mu \mathrm{M}\right)$. This indicates that PXR activation indeed can reduce the activity of cytotoxic Pgp substrates as a result of decreased intracellular accumulation.

\section{Discussion}

The development of MDR in response to anticancer treatment is a major problem in the clinic. Since induction of Pgp is one of the main mechanisms underlying acquired MDR, we evaluated whether several widely used anticancer drugs can induce Pgp expression via activation of PXR, a nuclear receptor that is increasingly associated with acquired MDR [9, 17].

Indeed, several anticancer drugs (vincristine, vinblastine, cyclophosphamide, ifosfamide, docetaxel, flutamide and tamoxifen) were shown to increase Pgp reporter activity in cells co-transfected with a PXR expression plasmid. In accordance, the same anticancer drugs induced Pgp protein expression in LS180 cells. However, when PXR was knocked down in these cells treatment with the indicated anticancer drugs did not result in Pgp protein induction. Together these results indicate that PXR plays a substantial role in anticancer drug-related Pgp induction.

Furthermore, since Pgp is a drug efflux transporter that is involved in the extrusion of a wide variety of substrates from the cell, the effect of Pgp protein induction following treatment with the indicated anticancer drugs on the intracellular accumulation of Pgp substrates was evaluated. Docetaxel, flutamide, paclitaxel and the positive control rif-
A
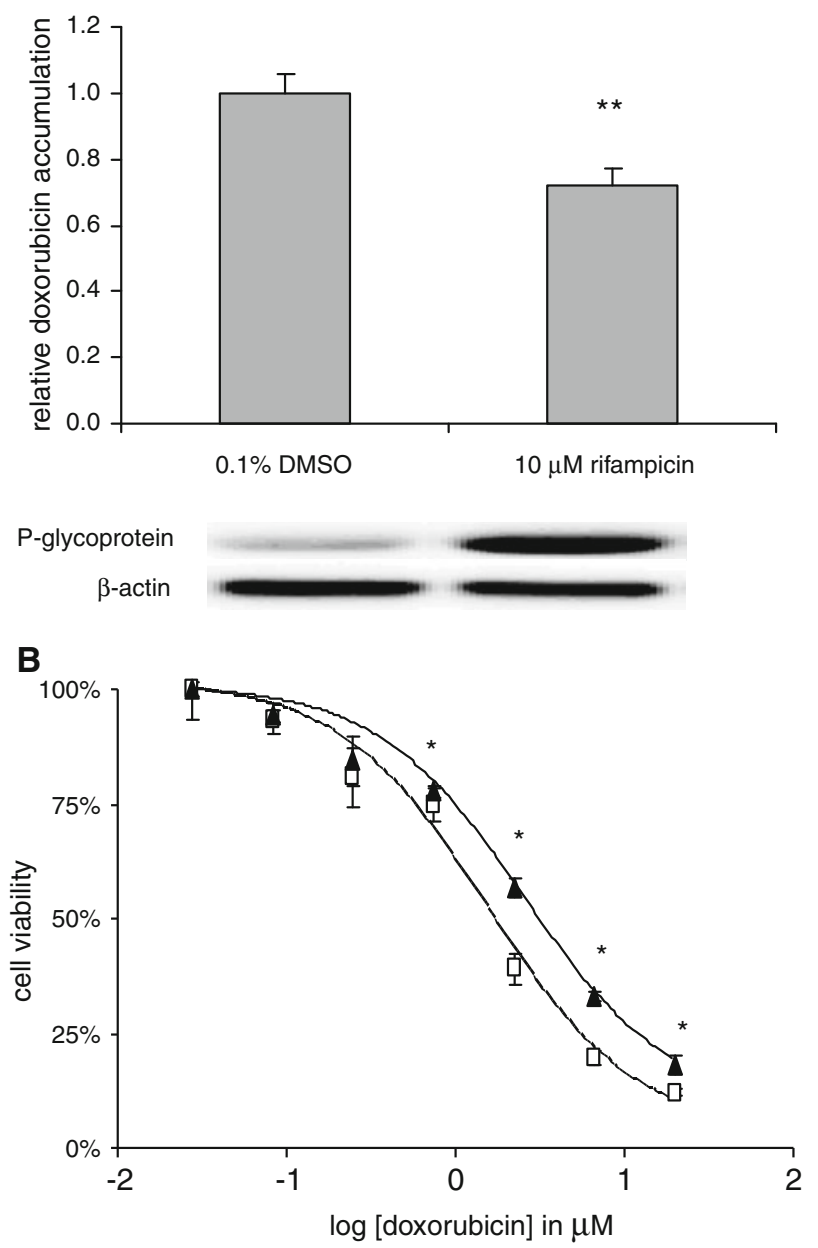

Fig. 5 a Rifampicin pretreatment decreases doxorubicin accumulation in LS180 cells. Doxorubicin accumulation was assessed in LS180 cells after $48 \mathrm{~h}$ pretreatment with rifampicin $(10 \mu \mathrm{M})$. These results are derived from a representative experiment and data are the means $( \pm \mathrm{SD})$ from three separate determinations and is expressed as fold decrease in doxorubicin accumulation compared to $0.1 \%$ DMSO $(* * P<0.01)$. b Rifampicin pretreatment reduces the cytotoxicity of doxorubicin in LS180 cells. The effect of $96 \mathrm{~h}$ rifampicin pretreatment on the cytotoxicity of doxorubicin in LS180 was determined with a neutral red assay. The results are presented as mean viabilities $( \pm \mathrm{SD})$ and are derived from four separate determinations $(P<0.05)$

ampicin that induced Pgp protein expression indeed affected the intracellular accumulation of the Pgp substrate rhodamine 123. In addition, carboplatin and etoposide, which had no effect on Pgp protein expression, did not affect rhodamine 123 accumulation. However, tamoxifen was shown to activate PXR-mediated Pgp protein induction, but did not affect the accumulation of rhodamine 123 . This can be explained by the fact that tamoxifen is also a known inhibitor of Pgp and thus prevents the Pgp-mediated extrusion of rhodamine 123 [18]. The observed discrepancy between the Pgp protein expression and Pgp functionality 
after treatment with the Vinca alkaloids is difficult to explain and requires further investigation.

Since activation of PXR by anticancer drugs was shown to affect the accumulation of Pgp substrates, we further assessed whether PXR activation could also attenuate the cytotoxic effects of doxorubicin, a known cytotoxic Pgp substrate. However, to avoid potential pharmacodynamic interactions between the selected anticancer drugs and doxorubicin that could lead to increased cytotoxicity, we chose to pretreat the cells with the prototypical PXR agonist rifampicin. Indeed, pretreatment of LS180 cells with rifampicin decreased the intracellular accumulation of the cytotoxic Pgp substrate doxorubicin and additionally significantly reduced the cytotoxic efficacy of this agent. These results indicate that activation of PXR-mediated Pgp induction by anticancer drugs can underlie the development of acquired resistance. This is further supported by studies of Chen et al. [9] and Gupta et al. [17], who have shown that activation of PXR promotes the multidrug resistant phenotype of prostate and ovarian cancer cell lines, respectively.

Since Pgp is co-expressed with PXR in important barrier tissues, such as the intestines and the liver, activation of PXR-mediated Pgp induction could affect the pharmacokinetic profile of (oral) anticancer drugs. Indeed, drug-drug interactions as a result of PXR-mediated Pgp induction have been reported. For instance, intake of St. John's wort, which contains the PXR agonist hyperforin, by healthy volunteers resulted in a 1.9-fold increase in the oral clearance of the Pgp substrate fexofenadine [19], while rifampicin pretreatment resulted in a 1.3- to 5.3-fold increase in the oral clearance of fexofenadine [20]. In the same manner, anticancer drugs that activate PXR might affect their own pharmacokinetics, but also that of other concomitantly administered (anticancer) drugs.

In conclusion, several widely used anticancer drugs were shown to activate PXR-mediated Pgp induction, and as a result affect the intracellular accumulation and cytotoxic activity of Pgp substrates.

Acknowledgments The authors would like to thank the Maurits and Anna de Kock foundation and the Nijbakker-Morra foundation for financially supporting this study.

\section{Conflict of interest statement None.}

Open Access This article is distributed under the terms of the Creative Commons Attribution Noncommercial License which permits any noncommercial use, distribution, and reproduction in any medium, provided the original author(s) and source are credited.

\section{References}

1. Sinicrope FA et al (1994) Relationship of P-glycoprotein and carcinoembryonic antigen expression in human colon carcinoma to local invasion, DNA ploidy, and disease relapse. Cancer 74(11):2908-2917

2. Sonneveld $P$ (2000) Multidrug resistance in haematological malignancies. J Intern Med 247(5):521-534

3. Punyammalee B et al (1997) Association of mdr1 gene expression with other prognostic factors and clinical outcome in human breast cancer. J Med Assoc Thai 80(Suppl 1):S162-S173

4. Synold TW, Dussault I, Forman BM (2001) The orphan nuclear receptor SXR coordinately regulates drug metabolism and efflux. Nat Med 7(5):584-590

5. Pfrunder A et al (2003) Gene expression of CYP3A4, ABCtransporters (MDR1 and MRP1-MRP5) and hPXR in three different human colon carcinoma cell lines. J Pharm Pharmacol 55(1):59-66

6. Masuyama $\mathrm{H}$ et al (2003) Expression and potential roles of pregnane X receptor in endometrial cancer. J Clin Endocrinol Metab 88(9):4446-4454

7. Mensah-Osman E (2005) Ecteinascidin-743 is a potent inhibitor of P450 3A4 enzyme and accumulates cytoplasmic PXR to inhibit transcription of P450 3A4 and MDR1: implications for the enhancement of cytotoxicity to chemotherapeutic agents in osteosarcoma. 2005 ASCO annual meeting

8. Dotzlaw H et al (1999) The human orphan receptor PXR messenger RNA is expressed in both normal and neoplastic breast tissue. Clin Cancer Res 5(8):2103-2107

9. Chen $\mathrm{Y}$ et al (2007) Human pregnane $\mathrm{X}$ receptor and resistance to chemotherapy in prostate cancer. Cancer Res 67(21):1036110367

10. Harmsen S et al. (2008) Comparison of two immortalized human cell lines to study nuclear receptor mediated Cyp3a4 induction. Drug Metab Dispos 36(6):1166-1171

11. Collett A, Tanianis-Hughes J, Warhurst G (2004) Rapid induction of P-glycoprotein expression by high permeability compounds in colonic cells in vitro: a possible source of transporter mediated drug interactions? Biochem Pharmacol 68(4):783-790

12. Shepard RL et al (2003) Modulation of P-glycoprotein but not MRP1- or BCRP-mediated drug resistance by LY335979. Int J Cancer 103(1):121-125

13. van Asperen J, van Tellingen O, Beijnen JH (1998) Determination of doxorubicin and metabolites in murine specimens by highperformance liquid chromatography. J Chromatogr B Biomed Sci Appl 712(1-2):129-143

14. DeGregorio MW et al (1984) Uptake, metabolism, and cytotoxicity of doxorubicin in human Ewing's sarcoma and rhabdomyosarcoma cells. Cancer Chemother Pharmacol 12(1):59-63

15. Repetto G, del Peso A, Zurita J (2008) Neutral red uptake assay for the estimation of cell viability/cytotoxicity. Nat Protoc 3:11251131

16. Dantzig AH et al (1999) Selectivity of the multidrug resistance modulator, LY335979, for P-glycoprotein and effect on cytochrome P-450 activities. J Pharmacol Exp Ther 290(2):854-862

17. Gupta D et al (2008) Expanding the roles for pregnane $X$ receptor in cancer: proliferation and drug resistance in ovarian cancer. Clin Cancer Res 14(17):5332-5340

18. Rao US, Fine RL, Scarborough GA (1994) Antiestrogens and steroid hormones: substrates of the human P-glycoprotein. Biochem Pharmacol 48(2):287-292

19. Dresser GK et al (2003) Coordinate induction of both cytochrome P4503A and MDR1 by St John's wort in healthy subjects. Clin Pharmacol Ther 73(1):41-50

20. Hamman MA et al (2001) The effect of rifampin administration on the disposition of fexofenadine. Clin Pharmacol Ther 69(3):114-121 